\title{
THE REPRESENTATION OF EXPERIENCE IN UNDERGRADUATE BUSINESS STUDENTS' TEXTS: A FUNCTIONAL ANALYSIS OF MULTIMODAL MEANING MAKING RESOURCES IN MARKETING TEXTS
}

\author{
Hesham Suleiman Alyousef
}

\begin{abstract}
From the Systemic Functional Linguistics (SFL) standpoint, experiential meanings reflect our experience, perceptions, and consciousness. Research on experiential meaningmaking in tertiary contexts has traditionally focused on areas such as mathematics, journalism and media, science and computing, nursing, and history. This paper aims to investigate the experiential multimodal meanings in an undergraduate marketing course. The data comprised three written assignments and the tutor's two model texts. The study employed a multidimensional approach by Alyousef (2013), which is framed by SFL (Halliday 2014) and O'Halloran's (2005, 1998, 2008, 1999) multisemiotic framework for the analysis of semiotic codes in mathematics. The results showed that the experiential meanings in the students' marketing plan texts were primarily construed through material processes and both explicit and implicit relational identifying processes. The findings indicated how mathematical symbolism is encoded in the multisemiotic texts, in the most economical manner, by using grammatical strategies of structural condensation. The results also noted the extent to which the different modes of meaning were integrated in the texts.
\end{abstract}

\section{Keywords}

Systemic Functional Linguistics (SFL), Systemic Functional Multimodal Discourse Analysis (SF-MDA), transitivity analysis, business discourse

\section{Introduction}

From the SFL standpoint, experiential meanings represent our experience, perceptions, and consciousness; therefore, these 'content' type meanings construe both our material and mental picture of reality. More simply, these kinds of meanings pertain to the content or topic of a text. Experiential meanings are expressed most obviously in the grammatical system of Transitivity with the particular configuration of Participants, Process, and Circumstances; these functional parts correspond with our understanding of 'what is going on', 'who is involved in the goings on', and 'what are the circumstances surrounding the goings on, such as when and where the going on is going on'. Text-based research in tertiary contexts has been confined to mathematics, journalism and media, science 
and computing, and nursing. For example, in her study of oral mathematical classroom discourse, O'Halloran (2005, 1998, 2008, 1999) contended that semantic extensions of experiential meanings in mathematical symbolism are characterized by 'condensatory' lexico-grammatical strategies, such as ellipsis, the introduction of multiple levels of rankshift, new 'Operative' processes with multiple mediums, metaphorical shifts between material and mental processes, and the deletion of the human agent. The new 'Operative' process encompasses algebraic mathematical operations and arithmetic operations, such as addition, subtraction, multiplication, and division. Circumstantial elements are not usually relevant. As the multimodal literacy and numeracy practices of marketing plan texts comprise numerical data, it is pertinent to employ O'Halloran's framework. These practices play a vital role in maximizing students' rich and broad learning experiences. Systemic Functional Multimodal Discourse Analysis (hereafter SF-MDA) investigations of tertiary business discourse have been limited to few authors. Alyousef and Alsharif (2017) conducted an SF-MDA of the experiential meanings in tertiary accounting texts. The findings showed that accounting discourse in financial statements is highly metaphorical due to the abundance of implicit relational identifying processes that are used for defining the value of accounting technical lexis. Mathematical formulae in Excel spreadsheets and financial tables utilize structural condensation to unambiguously encode mathematical symbolism in the most economical manner. Similar findings were also reported by Alyousef (2013) and Alyousef and Mickan (2016) in their SF-MDA investigations of tertiary finance and management accounting texts, which revealed that most of the process types were those of implicit relational identifying that had been factored into financial tables. Meanwhile, their studies also found that material process was the second most frequently occurring type. These findings of the two studies indicated that students were constrained by the ideological conventions for constructing financial tables, which employ structural condensation to encode meanings in the most economical manner.

Although marketing plan texts are one of the most commonly used genres in marketing, there is a lack of text-based investigations that explore the multimodal experiential meanings in tertiary texts. A review of the literature revealed that these texts have been investigated in only two studies (Alyousef 2016, Alyousef 2017), which conducted an SF-MDA to investigate textual meanings in international undergraduate student writing. The two studies examined, respectively, the patterns of Theme and Rheme and the use of cohesive devices. However, the system of Transitivity in tertiary marketing texts has not been documented.

This paper reports a case study of the multimodal texts, which are prevalent in the field of Marketing. Multimodal refers to the many modes or semiotic systems 
that are deployed to make meaning in this disciplinary context. Marketing texts routinely incorporate various information graphics, such as tables and figures; these are positioned alongside a written text where they complement and/or augment the written text in ways that enhance the overall meaning. The different modes are used to work together; accordingly, the term intersemiotic complementarity (Royce 2002) describes this process. The main aim of the present study is to describe the representation of the dynamic multimodal experiential meanings in a key topic in an undergraduate marketing course, namely a marketing plan project. This is achieved by employing the multidimensional approach proposed by Alyousef (2013). The data included a tutor's two model texts and three major individual assignments written by international students in their final year of study of a Business Management (Marketing) undergraduate program. The texts centered on The Marketing Plan in a course titled Integrated Marketing Topics. The focus is on the interrelated dimensions of multisemiotic texts, to highlight the ways in which different semiotic systems are integrated to produce experiential meanings.

\section{Methodology}

The study employed the multidimensional approach by Alyousef (2013) for the analysis and interpretation of students' multimodal literacy practices. This approach is informed by the SFL understanding of language as a social semiotic (Halliday 2014) and also by O'Halloran's $(2005,1998,2008,1999)$ framework for the analysis of experiential meanings in the numerical data of the marketing plan texts. The process involves the following three stages:

- Describing the aims of the marketing plan text: the requirements of the assignment task and its graduate attributes and learning outcomes

- Analyzing the experiential multimodal meanings within the texts and the tables and figures through an SF-MDA

- Documenting the students' experiences and their accounts of working with marketing texts

The first stage examined the conceptual and linguistic demands in the major written assignment. An SF-MDA and interpretation of the student texts were then undertaken. This stage aimed to investigate the representation of multimodal experiential meanings to derive evidence of the students' understanding of experiential meanings underlying the marketing plan discourse. The third stage entailed individual student reflections on how they used the marketing texts via structured interviews to elicit their perceptions and experiences of the assignment's writing requirements. 
The SF-MDA was developed from Halliday's (2014) SFL and details a range of resources for analyzing and interpreting multimodal meanings in texts. Underpinning these analytic resources are the three metafunctions that provide the organizing framework through which language users make three broad and general kinds of meanings. This SFL framework suggests that language is organized to make:

- 'Experiential meanings' by representing and ordering our experiences, perceptions, consciousness

- 'Interpersonal meanings' by enacting social roles and relationships amongst participants

- 'Textual meanings' by organizing experiential and interpersonal meanings into a coherent and cohesive unified text

These metafunctions or generalized kinds of meaning are evident through different lexico-grammatical systems. The metafunctions also correspond to three register variables of Field, Tenor, and Mode. Experiential meanings are made in relation to Field, or what the focus or content of the activity happens to be. Second, interpersonal meanings are revealed through Tenor, which shows how social roles and identities are constructed. Finally, textual meanings relate to the Mode of a text, which weaves the experiential and interpersonal meanings into a coherent and cohesive unified text. In this way, SFL provides a theoretical and practical linkage for understanding the relationship between the context of language use and choices from the systems of grammar which are made in such a context.

In order to successfully complete the marketing plan report, students need to acknowledge the three register variables to understand the demands of the context for the assignment, make appropriate choices of meaning from the experiential, interpersonal, and textual metafunctions, and then express these through appropriate choices from the different systems of grammar. The representation of the multimodal experiential meanings (Stage 2) is informed by the SF-MDA of the Transitivity choices in the students' and tutor's texts. Transitivity patterns in the texts offer evidence of the students' understanding of the Field in the key topic within the Integrated Marketing Topics course, namely the marketing plan. The marketing plan constitutes the Field, and through the control of the Transitivity system, we see evidence of the experiential meanings that have been selected to show understanding of the content of this topic.

At a common sense level, Transitivity provides understanding of the process or activity that is at the heart of the enquiry - essentially the understanding of 'what is going on in the text' or 'what information the writer does present'. The analysis involves categorizing the processes encoded in each verb, noting 
The Representation of Experience in Undergraduate Business Students' Texts: A Functional Analysis of Multimodal Meaning Making Resources in Marketing Texts

the Participants who or which are very closely engaged with the process, and then finally any circumstances that provide contextual information about the Participants and the process. In this way, Transitivity selects the different process types, which engage with different Participant types in activities under different types of circumstance.

The different categories of each process involve specific participant roles. For example, material processes are those of action, and may engage two specific participant roles, namely as Actor and Goal. Processes that operate with two Participants are labeled as di-transitive and those with one Participant as monotransitive. The Actor participating in material processes is the 'doer' and the Goal is the 'done to', namely, the person or thing that is directly affected by the process. The Circumstances provide the contextual parameters of the process, for example, when and where the processes play out. They are expressed by prepositional or adverbial phrases, for example in the next four years.

The Participants, Processes, and Circumstances were manually coded in the students' and tutor's texts in order to highlight any salient patterns. This was undertaken for both the written language and tables and graphs. Here, the multimodal nature of the texts became relevant. Marketing texts ordinarily use graphs and tables to make experiential meanings. They are used to represent synthesized and distilled experiential information, which is difficult to represent through written text. Very often, the accompanying (or surrounding) written text of tables and graphs explicates their meanings. This may be necessary because these meanings are implicit. The task here was to interpret the experiential meanings within the tables and graphs, and to do this, I assigned an explicit Transitivity reading. The students' intuitive interpretations (or reading path) of the tables and figures were used to externalize the inherent meanings.

The data set comprised three major individual assignments and two model texts from a tutor on marketing plan that was comprised of multimodal written texts. The three assignments were written by three international students enrolled in a Business Management (Marketing) undergraduate program. The following fictitious names were used to ensure anonymity: Wafa, Maram, and Dalal.

\section{Findings}

\subsection{The marketing plan task}

To develop an understanding of the marketing plan task, I examined the requirements of the assignment task, the graduate attributes, and the learning outcomes. 


\subsubsection{Nature of the marketing plan major assignment}

The terms 'marketing plan' and 'market planning' (or in general, 'business planning') are used interchangeably to refer to "a technology or a set of techniques and activities that assists an organization in achieving an appropriate alignment of external environment and internal capabilities in order to achieve a desired outcome" (Pulendran et al. 2003: 478). Businesses need a marketing plan to detail analyses, ideas, and plans that are linked to a company's goals and strategies. The marketing plan also communicates the essentials of the marketing initiative and the professionalism of its author(s) to other areas of the organization.

The tutor grouped the class into five competing automobile industry groups (or competitors): A1, B1, C1, D1, and E1. Each group comprised three to five students, who were responsible throughout the course duration to run their simulation StratSim Marketing (SSM; cf. https://interpretive.com/rd6/?pg=ssm4), the interpretive software based on a hypothetical automobile company. SSM aims to provide students with practical experience in dealing with the intricacies of competition. The three participants in the present study comprised one of the five automobile industry groups. Each group conducted 3-4 one-hour meetings to discuss the SSM results. The groups evaluated their product's performance (e.g. net income and return on sales) during these meetings in order to make decisions. Decisions were made for each simulated fiscal year. Once all the competitors had made these annual decisions, the simulation was advanced, and the results were updated. These results were dependent on group decisions, those of other competitors, and the evolution of the market. The SSM provided a 'semiotic metaphor' for this literacy and numeracy event. It enabled the students to apply their learning to a range of situations that resembled workplace practices. Chandrasoma (2007: 133) termed this type of task as "technocentric" since it is "characterized by the predominant appropriation of new technologies of communication". As Baker, Street and Tomlin (2003: 12) noted, numeracy events are "occasions in which a numeracy activity is integral to the nature of the participants' interactions and their interpretative processes". The students were also required to refer to the textbook, Essential Guide to Marketing Planning (Wood 2013), and at the end of the semester, they were required to write an individual four-year business marketing plan for an automobile company within 3,000 words to demonstrate their understanding of marketing as a part of the overall business management. In addition, each group was required to create a presentation at the end of the semester.

The students were provided with detailed instructions on the content, the required schematic structure of a marketing plan report, its professional language 
style, and general format guidelines. The tutor provided the schematic structure of a product marketing plan as well as the content of each structural element. The schematic structure is as follows:

\section{Executive Summary}

2. Corporate Strategic Focus (i.e. 'where are we now?'): SWOT Analysis.

3. Situation Analysis

4. Product-Market Focus

5. Marketing Program (i.e. 'where do we want to go?'): Objectives

6. Financial Data and Projections (i.e. 'how do we go about it?'): Marketing Strategy

7. Implementation and Management of the Plan

8. Evaluation and Control

Corporate Strategic Focus specifies the company's financial, marketing, shareholder, and societal measurable objectives. It includes analyses of the situation through SWOT, a comprehensive summary of the existing internal strengths and weaknesses, and the external situation vis-à-vis opportunities and threats, based on the information in the SSM. This is represented in Figure 1.

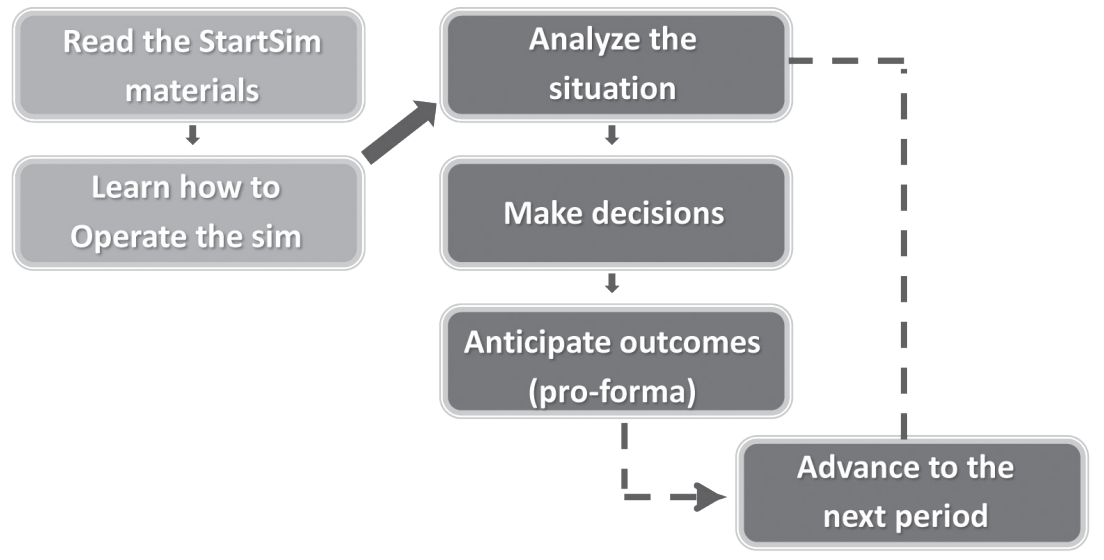

Figure 1: Getting started with the simulation

Figure 1 presents the experiential meanings and conceptual processes underlying the SSM: these include both material (reading the materials) and mental (learning, analyzing, making decisions, and anticipating outcomes) processes, 
i.e. processes that require physical action and cognition. The SWOT analysis details an organization's strengths which reveal its capabilities or factors that can help in achieving its objectives, capitalizes on opportunities, and deflects threats and weaknesses that may prevent an organization from achieving its objectives. The SWOT analysis also manages opportunities and threats: opportunities refer to any external circumstances or factors that can be exploited to achieve the objectives, and threats highlight external circumstances that inhibit the achievement of objectives, if not addressed. The students were also provided with general formatting and style guidelines. On the matter of language style, students were required to adhere to the following:

- Use a direct, professional writing style

- Use active voice, be positive and specific ( $I$ ) (avoid judgment words such as terrific or amazing, which would be identified as evaluative language, and definitely avoid phrases such as I hope to be successful...)

- Use bullet points for succinctness and emphasis (not as the main writing style)

- Use tables/figures when appropriate and comment on them within the text (provide a 'story')

\subsubsection{The graduate attributes and learning outcomes of the marketing plan task}

The graduate attributes of the marketing plan major assignment include the following:

- Knowledge and understanding of marketing

- Critical thinking and analytical skills in creative marketing solutions, as well as

- Interpersonal and written communication skills

The individual marketing plan report was allocated 60 per cent of the total mark for the course, and 40 per cent was allotted for the group presentation. The SSM software is purported to develop the following skills:

- Develop a market-oriented perspective

- Develop and implement a profitable long-term marketing strategy

- Operate in a competitive environment

- Identify customer needs and creating products to satisfy them

- Analyze competitors and understanding their strategic intent 
The Representation of Experience in Undergraduate Business Students' Texts: A Functional Analysis of Multimodal Meaning Making Resources in Marketing Texts

- Apply marketing research tools and techniques as a source of competitive advantage

- Allocate scarce resources among products, functions, and other investment alternatives

The learning outcomes for using the SSM are stated in terms of the multimodal tasks that the students needed to manage, and the processes that required action (learn, develop, operate, identify, analyze, apply, and allocate). Different automobile companies were positioned as high-end niche producers, whereas others were more value and volume driven. Each company began the simulation with three vehicles and then was required to decide on how best to improve the company's performance and potentially enter new market sectors that offered opportunities for growth. Each company's performance was judged by the following criteria:

- Net Income and Cumulative Net Income

- Stock Price

- Total Shareholder Return

- Return on Equity, Return on Assets, Return on Marketing

- Earnings Per Share

- Market Share

- Return on Sales

The simulated business market provided the context for the student groups to learn about marketing plans and then produce their written reports. What follows is an SF-MDA of the experiential meanings within these multimodal texts.

\subsection{An SF-MDA of the experiential meanings in the texts}

The sentential participants' roles in the two data sets were all occupied by inanimate entities, such as amazing cars, efficient motor, blue sky, marketing plan, marketing campaigns, marketing program, market spending, marketing trend, marketing methods, corporate marketing resources, and industry marketing expenditures. The participants in the present study assumed that they share with their readers specialist or expert knowledge, as evidenced by their use of abbreviations and acronyms of technical terms that carry meanings not generally known by the broader community, such as GDP (Gross Domestic Product), MSRP (Manufacturer's Suggested Retail Price), COGS (cost of goods sold), HP (horsepower), and $R \& D$ (research and development). The use of these specialist terms assumes insider knowledge of the subject, and these terms are 
typically modified by classifiers that tend to be organized in mutually exclusive and exhaustive sets (Halliday 2014): for example, the classifier gross in gross domestic product places the item product in a subclass of products, distinguishing it from gross domestic income. The texts also included terms that do not assume expert knowledge such as sales, advertising and promotion, products, customers, interest rate, safety, and vehicle.

The SFL principle maintains that the Transitivity patterns in the texts offer evidence of the students' understanding of the marketing plan topic in the Integrated Marketing Topics course. The analysis highlights the choices made for Participants, Processes, and Circumstances, which reveal the linguistic content of the report made by the students.

Table 1 presents the frequency of process types in the students' and the tutor's multimodal marketing plan reports. The SF-MDA of the written elements revealed that material processes were the most frequently occurring process type, followed by relational attributive processes in the students' texts and relational identifying processes in the tutor's texts. Material processes involve some form of material action, as they describe processes of doings and happenings, as in "Two main types of market segment [Actor] purchase [Pr: Mat.] Estruck [Goal]" (Dalal's Text). Relational processes of being can be either identifying or attributive; they are either used for identification or description and classification. A relational identifying clause identifies an entity by equating it with some other entity, which serves to distinguish or single it out, as in "The hot buttons to segment consumers [Token: Identified] are [Pr: Rel., Identifying] safety and quality [Value: Identifier]" (Wafa's Text). The participants in a relational identifying clause are reversible, whereas they are not in a relational attributive clause, as in "The family segment [Carrier] is [Pr: Rel., Attributive] the highest [Attribute]" (Maram's Text). Here, Maram described the family segment in Amazing Car Company as being the highest among all firms in this class. The findings of the SF-MDA of the students' and the tutor's tables and figures revealed that the most frequent process type was implicit relational processes, which were interpreted as relational identifying (91.44 and 77.88 per cent, respectively), whereas material processes were the second most frequently occurring process type (Table 1). 


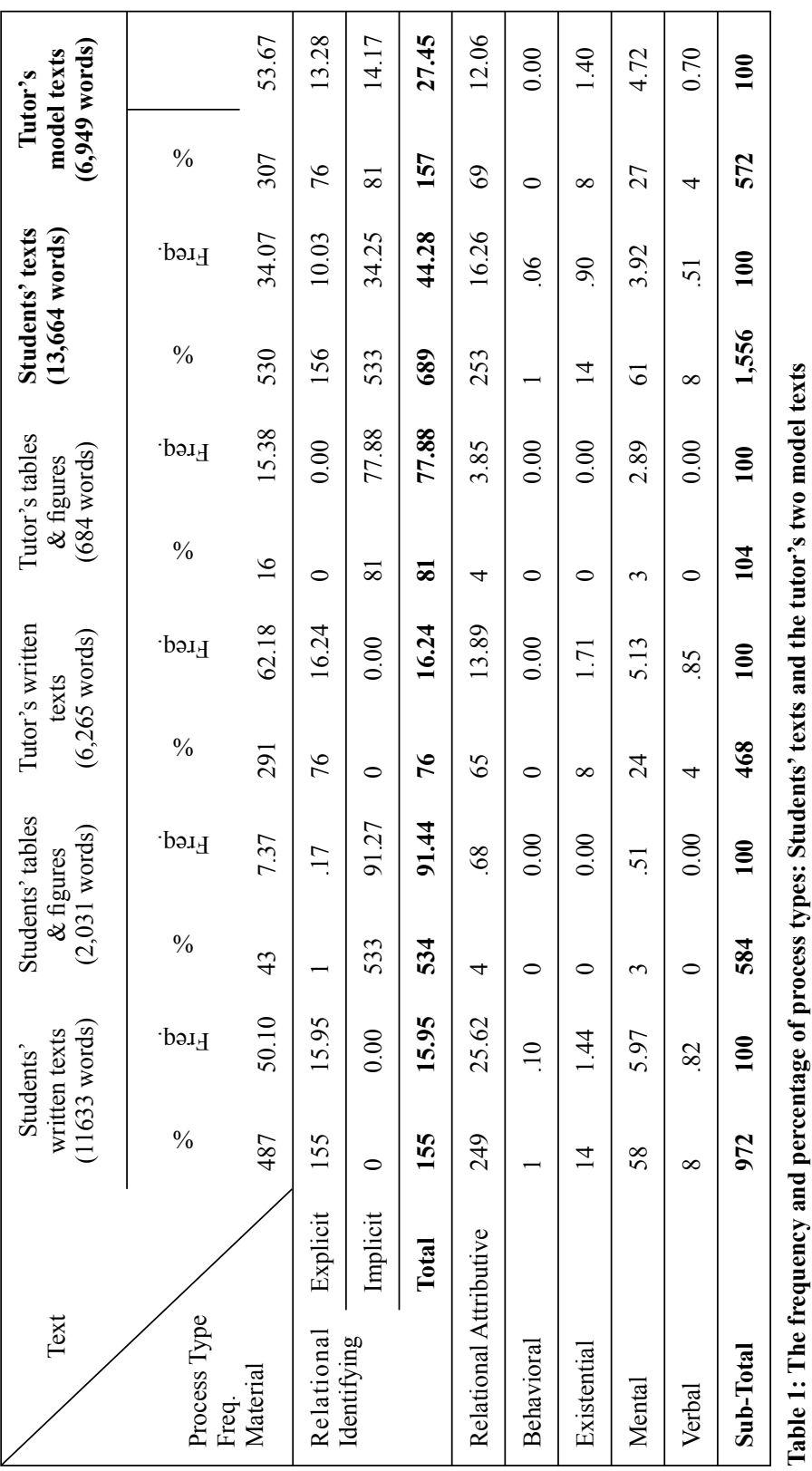


The SF-MDA indicated that the discourse in the marketing plan texts is highly interpretative using implicit relationships between Token and Value to refer to the participants in a relational identifying clause; examples from the data are given in Table 2 .

\begin{tabular}{|c|c|c|c|c|}
\hline Text & No. & Token-Identified & $\begin{array}{l}\text { Process: Implicit, } \\
\text { Relational-Identifying }\end{array}$ & Value-Identifier \\
\hline \multirow{3}{*}{ 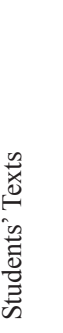 } & 1 & $\begin{array}{l}\text { - Total sales in Period } 5 \\
\text { - Overhead projection in Period } 5\end{array}$ & $\begin{array}{l}\text { [equals] } \\
\text { [equals] }\end{array}$ & $\begin{array}{l}\$ 8,585,000,000 \\
\$ 639,000,000\end{array}$ \\
\hline & 2 & $\begin{array}{l}\text { - The GDP in Period } 3 \\
\text { - Past sales revenue in Period } 1\end{array}$ & $\begin{array}{l}\text { [equals] } \\
\text { [equals] }\end{array}$ & $\begin{array}{l}2.0 \\
\$ 20,516\end{array}$ \\
\hline & 3 & $\begin{array}{l}\text { - Dealer Sales ( } \$ \text { mil.) projection in } \\
\text { Period } 6 \\
\text { - The manufacturer's suggested retail } \\
\text { price (MSRP) projection in Period } 9\end{array}$ & $\begin{array}{l}\text { [equals] } \\
\text { [equals] }\end{array}$ & $\begin{array}{l}\$ 5,529 \\
\$ 21,399\end{array}$ \\
\hline \multirow{2}{*}{ 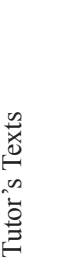 } & 1 & $\begin{array}{l}\text { - Annual Sales projection in the third } \\
\text { year for Blue Sky Clothing } \\
\text { - The new outlets added in second } \\
\text { year }\end{array}$ & $\begin{array}{l}\text { [equals] } \\
\text { [equal] }\end{array}$ & $\begin{array}{l}\$ 3.2 \text { million } \\
50\end{array}$ \\
\hline & 2 & $\begin{array}{l}\text { - Interest expense for the first year } \\
\text { - Motor vehicle expenses in the first } \\
\text { year }\end{array}$ & $\begin{array}{l}\text { [equals] } \\
\text { [equal] }\end{array}$ & $\begin{array}{l}\$ 2,250 \\
\$ 9,600\end{array}$ \\
\hline
\end{tabular}

Table 2: Examples of implicit relational identifying processes in the tables and the figures

Relational identifying clauses add further information, and take the form $x$ equals $y$ in what is labeled as a "thematic equative" structure (Halliday 1967). This structure is linked by a relationship of identity, expressed by the verb be or another verb expressing a similar meaning that has two identification functions: "a 'thing to be identified' and an 'identifier', that with which it is to be identified" (Halliday 1967: 224). Wafa's four-year projections (Table 3) included five instances of implicit relational identifying processes in each row, thus yielding 50 implicit instances in total. For example, the meanings in Table 3 can be made by use of relational identifying processes. Accordingly, for example, in Column 1 each of the items listed the sales (in dollars) for each of Periods 5-9. The actual Sales for each Period need to be explicit, that is to be identified, and in Period 5, it is identified by the amount $\$ 8,585,000,000$. This interpretation is congruent with the spoken mode of the accounting tables. 
The Representation of Experience in Undergraduate Business Students' Texts: A Functional Analysis of Multimodal Meaning Making Resources in Marketing Texts

\begin{tabular}{|lccccc|}
\hline Column 1 & Period 5 & Period 6 & Period 7 & Period 8 & Period 9 \\
\hline Sales & $\$ 8,585,000,000$ & $\$ 9,014,250,000$ & $\$ 9,464,962,500$ & $\$ 9,938,210,625$ & $\$ 10,435,121,156$ \\
\hline COGS & $\$ 6,334,000,000$ & $\$ 6,524,000,000$ & $\$ 2,442,000,000$ & $\$ 2,442,000,000$ & $\$ 2,442,000,000$ \\
\hline Margin & $\$ 2,251,000,000$ & $\$ 2,490,250,000$ & $\$ 7,022,962,500$ & $\$ 7,496,210,625$ & $\$ 7,993,121,156$ \\
\hline Expenses & & & & & \\
\hline Marketing & $\$ 95,000,000$ & $\$ 145,000,000$ & $\$ 145,000,000$ & $\$ 145,000,000$ & $\$ 145,000,000$ \\
\hline R\&D & $\$ 1,392,000,000$ & $\$ 1,392,000,000$ & - & - & - \\
\hline $\begin{array}{l}\text { General \& } \\
\text { Administrative }\end{array}$ & $\$ 988,000,000$ & $\$ 988,000,000$ & $\$ 988,000,000$ & $\$ 988,000,000$ & $\$ 988,000,000$ \\
\hline Overheads & $\$ 639,000,000$ & $\$ 639,000,000$ & $\$ 639,000,000$ & $\$ 639,000,000$ & $\$ 639,000,000$ \\
\hline Depreciation & $\$ 639,000,000$ & $\$ 639,000,000$ & $\$ 639,000,000$ & $\$ 639,000,000$ & $\$ 639,000,000$ \\
\hline & $\$ 3,753,000,000$ & $\$ 3,803,000,000$ & $\$ 2,411,000,000$ & $\$ 2,411,000,000$ & $\$ 2,411,000,000$ \\
\hline & & & & & \\
\hline Income from & $\$ 6,004,000,000$ & $\$ 6,293,250,000$ & $\$ 9,433,962,500$ & $\$ 9,907,210,625$ & $\$ 10,404,121,156$ \\
\hline
\end{tabular}

Table 3: Wafa's 4-year projections

Implicit relational processes in the marketing plan texts are also used to identify the value of terms that are related to past sales and financial forecasts of costs, which include exploratory costs, such as consultants, publications, and legal fees, and initial costs such as lease, electricity, gas and phone, and wages. These items in Column 1 realize the 'things to be identified'.

The Past Sales Revenues Projection in the stacked bar chart in Wafa's text (Figure 2) can be interpreted as meaning "revenues in Period 1 of the past 5 years [were] $\$ 8,000$ million", "revenues in Period 2 of the past 5 years [were] $\$ 7,200$ million", "revenues in Period 3 of the past 5 years [were] $\$ 7,050$ million", "revenues in Period 4 of the past 5 years [were] $\$ 8,050$ million", and "revenues in Period 5 of the past 5 years [were] $\$ 8,500$ million". 


\section{Past 5 years revenues}

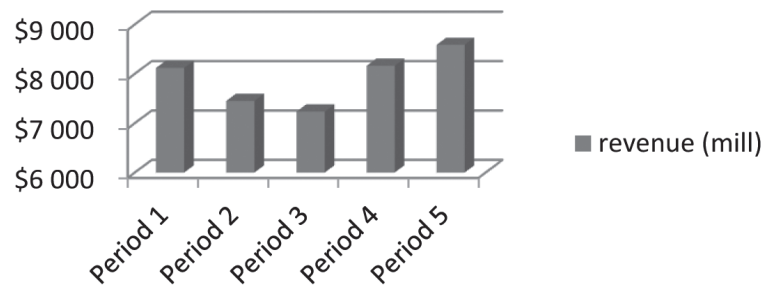

Figure 2: Wafa's past sales revenues projection

Halliday (2014) argued that the Value-Token structure plays an important role in highly valued registers such as commercial, scientific, bureaucratic, and political discourse, "where the meanings that are being construed are inherently symbolic ones" (Halliday 2014: 284). The reading path in the chart above directs the viewer first to the five bars indicating revenue. Following the English spatial dimension, the viewer then reads from left to right, beginning with each value in the vertical axis and its corresponding period along the horizontal axis in order to compare revenues for Periods 1-5. Based on the data in the bar chart and in her written text accompanying this figure, Wafa inferred that "no action was taken with the product in Periods 2 and 3". In Periods 4 and 5, she wrote that "revenues increased, which is a good predictor that Alec is performing well due to the changes and actions that were taken". Wafa showed her authorial presence through her comment "a good predictor that Alec is performing well". Authorial presence or stance refers to the writer's relationship to the claims made. The findings indicate that the experiential meaning in the figure was created not only intrasemiotically (i.e. within a figure or table) by comparing each numerical value with its corresponding period, but also through the intersemiotic relation that exists between visual semiotic resources and the text accompanying them. In other words, the visual semiotics aided Wafa in supporting her financial decisions in the marketing plan report by helping her explain the reasons underlying the increase in revenue. Since the figure prompted her to draw conclusions, the figure-text relationship is one of 'enhancement'. According to Martinec and Salway (2005), an 'enhancement' relationship is created between an image and a text if the former prompts information such as how, when, where, or why the text is taking place.

Dalal illustrated the market share details for Estruck and Detonka (Figure 3). She interpreted this figure as follows: "The market share of Estruck decreased 
The Representation of Experience in Undergraduate Business Students' Texts: A Functional Analysis of Multimodal Meaning Making Resources in Marketing Texts

steadily from Period 1 to Period 3 but increased in Period 4 and then decreased again in Period 5".

\section{Market Share Detail in Truck Market}

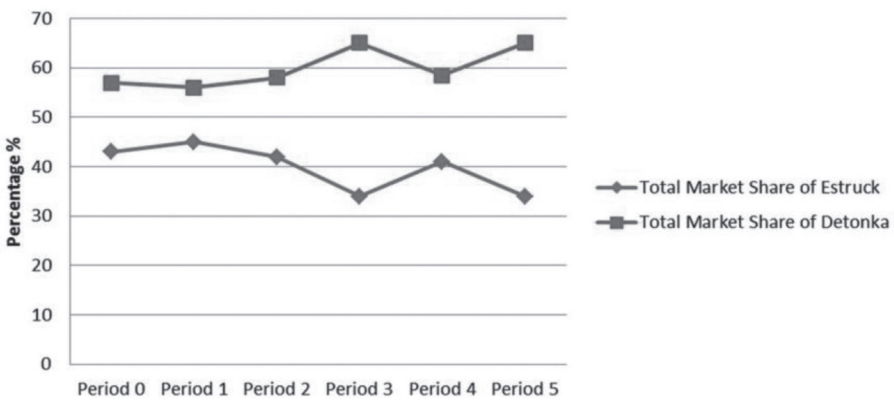

Figure 3: Dalal's market share details for Estruck and Detonka

Dalal wrote:

Market share increased in period 4 because we decreased our price to $\$ 19,700$ for upgrading (which was lower than Detonka's \$20,342). However, the market share decreased again in period 5 after we finished major upgrades and increased the price. As most of our consumers are 1T (value seekers) who are highly price sensitive, the increase in price decreased their buying powers. Although we are not in an intensive market, it is still hard for us to overweigh the sales of Detonka as they have lower price and higher dealer coverage rate in our sales lagging areas (East and West). In period 2, in the East region, their unit market share is $67 \%$ whereas ours was $33 \%$. In the West region, their unit market share was $63 \%$, whereas ours was $37 \%$.

The market share details data in Figure 3 supported Dalal's analysis in not only describing the market share of the truck company Estruck and its competitor Detonka during the five periods, but also spotting trends and providing interpretive analytical analysis in the accompanying text. This assisted Dalal in drawing conclusions that include explicit semiotic processes requiring action: "Hence, we need to establish dealers in these regions to improve our sales and enhance the dealer relationship".

The visual semiotic resources used in the texts are "conceptual" since they represent some kind of classification or analysis (Kress \& Van Leeuwen 2006). Dalal presented the economic outlook (or projection) for Period 6, instead of Periods 6-9. The use of relational attributive processes in the students' texts and the tutor's model texts was mostly confined to the written texts. 
(1) Alex [Carrier] posses [Pr: Rel, Attrib] better and more desirable attributes [Attribute]. (Wafa's Text)

(2) The company [Carrier] is [Pr: Rel, Attrib] an excellent standard of industry [Attribute]. (Maram's Text)

(3) Estruck [Carrier, Possr] currently only has [Pr: Rel, Attrib, Poss] one competitor [Attrib, Possd]. (Dalal's Text)

(4) An overdraft [Carrier] was agreed to be [Pr: Rel, Attrib] the most suitable arrangement [Attribute] for the first year [Circumstance: Temporal]. (The tutor's Model Text 2)

As stated earlier, these processes are used for description and classification, but as indicated in Table 1, relational attributive processes were minimally used in the two data sets. For example, Figure 4 shows Maram's analysis of Alfa's advertising and promotion from Period 6 to 9. The advertising and promotion slopes represent relational attributive processes that are interpreted in terms of their degree of steepness, that is, upward or downward to represent an increase or decrease respectively. The slopes can be interpreted in language as the advertising and promotion budgets [Carrier] will [Pr: Rel, Attrib] gradually increase [Attribute] from Periods 6 to 9 [Circumstance: Temporal]. This mono-transitive clause has only one inanimate participant (i.e. advertising and promotion budgets), about which information is provided through a circumstance of time.

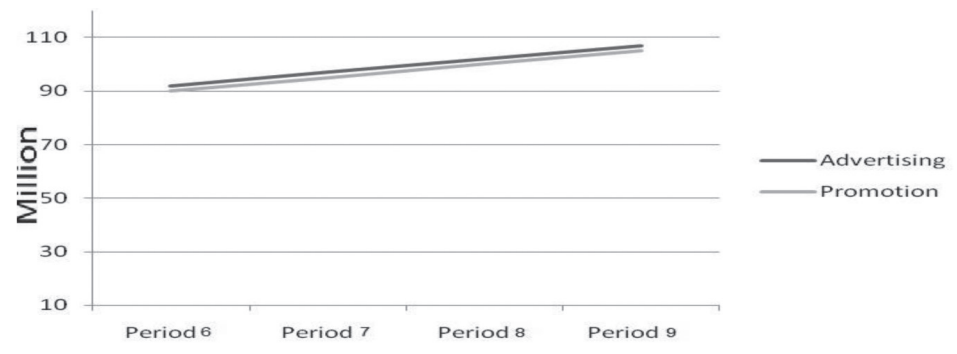

Figure 4: Maram's analysis of Alfa's advertising and promotion from Period 6 to 9

Maram commented in her written text that this growth is "in line with Alfa sales growth". The figure-text relationship, therefore, is one of 'enhancement'. The figure above prompted information related to how the numbers of the company's advertising and promotion sales growth from Period 6 to 9 are equal. This figure enhanced the meaning in the orthographic text. 
The Representation of Experience in Undergraduate Business Students' Texts: A Functional Analysis of Multimodal Meaning Making Resources in Marketing Texts

The overall findings of the SF-MDA (Table 1) revealed that the students used more explicit and implicit relational identifying processes in their texts than did their tutor (44.28 per cent vs. 27.45 per cent, respectively), although the total number of tables and graphs in the two data sets was very similar, as shown in Table 4.

\begin{tabular}{|lccccccc|}
\hline & \multicolumn{3}{c}{ Students' texts } & & Tutor's model texts & \multicolumn{2}{c|}{ Total } \\
\cline { 2 - 8 } & Wafa & Maram & Dalal & $\begin{array}{c}\text { First } \\
\text { text }\end{array}$ & $\begin{array}{c}\text { Second } \\
\text { text }\end{array}$ & Students & Tutor \\
\hline Tables & 2 & 9 & 9 & 9 & 8 & 20 & 17 \\
\hline Graphs & 3 & 1 & 2 & 2 & 3 & 6 & 5 \\
\hline Total & 5 & 10 & 11 & 11 & 11 & 26 & 22 \\
\hline
\end{tabular}

Table 4: The tables and graphs used in the five texts

In the tutor's writing, material processes were the most common (53.67 per cent). This could be ascribed to the fact that the tables in the tutor's texts did not include all the numerical values. As the tutor's texts functioned as a student guide, it was normal for most of the cells in the tables to be blank. Furthermore, one of the tutor's model texts had more material processes in the tables and figures because the SWOT analysis was presented in a figure format, rather than within the written text, which was different from the students. These findings indicate that marketing plan texts intertwine both relational identifying and material processes. One point of interest in Table 4 is the clear difference in the use of tables by Wafa in comparison to her peers and the tutor. Wafa preferred to place the tables in the appendices, while presenting and discussing her findings in the text.

The Transitivity analysis revealed that only Wafa presented mathematical formulae to show her calculations. She used the mathematical single "Operative" process " $15 \mathrm{x} \$ 20=\$ 300$ " to calculate the total cost of opening 15 new dealers, where \$20 represents the cost of \$20 million dollars for opening each one. This mathematical statement consists of the "Operative" material process represented by the multiply sign (' $x$ ') and an implicit relational identifying process exemplified by the equal sign: "Total cost [Token: Agent, Identified] $=$ [Process: Relational Intensive Identifying] 15 [Participant: Actor] x [Pr: Material] \$20 [Participant: Goal] $=$ [Process: Relational identifying] \$300 million [Value: Identifier]". The finding that "Operative" processes in mathematical symbolism include multiple mediums (or participants) contrasts with Halliday's notion of 
a single central medium. The medium consists of what O'Halloran (1999: 5) called "multiple mediums connected with operative processes as opposed to the notion of a single medium found in the process types of natural language". Mathematical symbolism is characterized by a narrow range of processes and "the absence of a periphery realizing circumstance" (O'Halloran 1999: 10). As stated earlier, expressions in mathematical statements do not include circumstances that add meaning, and they consist of relational identifying and operative material processes (e.g. addition subtraction, multiplication, and division).

\subsection{Students' perceptions of the assignment}

The literacy and numeracy demands of marketing plan reports require a repertoire of practices that are based on complex sets of discourses, identities, and values. Wafa reflected that she worked very hard to achieve the 81 per cent she received in this course. Maram's and Dalal's marks were 72 per cent and 75 per cent, respectively. Such achievements indicate that the students successfully used marketing research tools and techniques, which included developing a profitable long-term marketing strategy, analyzing their competitors, understanding their strategic intent, and identifying customer needs and creating products to satisfy these needs. For example, Wafa compared her experiences in doing this marketing plan with another one she was asked to construct in her real-life job in the following:

"I spent less time writing a marketing plan for my job. It was on an industrial city ... mmm about six hours. I read about the project. I was more confident and not nervous. It's more difficult to make an estimation of an industry when you do not have the experience."

All the three participants did not face any problems in working out the schematic structure of the written assignment, as it was provided by the tutor in the task sheet (cf. Section 3.1.1), in addition to the content of each structural element.

The first task with which Wafa engaged when doing the assignment was researching the topic using the textbook and the Internet. She also worked to understand the SSM material. Wafa often consulted her group members in order to seek clarification of ambiguous points. She was reluctant to consult her tutor lest he should have a bad image about her level. This finding contrasts with Jones' (1999) study, which attributed some EFL/ESL students' passivity and reticence to communicate effectively to their language competency level. Maram read the task sheet and the model marketing plan several times in order to gain insight 
The Representation of Experience in Undergraduate Business Students' Texts: A Functional Analysis of Multimodal Meaning Making Resources in Marketing Texts

of the topic and the task requirements. She then read the model marketing plan text again and made notes related to the schematic structure of the report and the content within each heading. Dalal found it challenging to paraphrase the texts. As paraphrasing is a technical task required of the students, Dalal decided to develop this skill by seeking support from colleagues, the Internet, and the university's writing center.

The choices made by the students from different semiotic systems of language and numbers are indicators of cross-disciplinary knowledge, as they also include knowledge of accounting and the SSM. The students were also required to employ their experience of two prerequisite marketing courses: Essentials of Marketing Planning and Marketing Analytics. All the three students were influenced by their previous experience in not only the accounting course and the two prerequisites, but also other courses, such Market Research and Market Analysis. They were also influenced by their tutor's comments on the SSM outcome, as he compared their decisions with those of the other groups and gave them some tips. Although the SSM aimed to provide students with practical experience, the three participants believed that it would have been better if they had the chance to gain such experience through authentic situations (or real companies), rather than hypothetical ones. For example, Wafa stated that working with employees in a real company is much better, as you will have the opportunity to learn from their experience. In her answer to the question on the applicability of such a task in real life, Wafa commented that everyone needs to set up goals in his/her life, including the stages through which these can be achieved, rather than taking quick decisions that are vulnerable to failure. The participants also thought that this task relates to work situations. Any organization needs to have consistent strategies that represent its vision in order to achieve a strong position in the market by utilizing a number of marketing reports, including marketing plans, strategies and plans, advertising, and market study research. All three participants were not very happy with their grades, and their main concern was that it affected their overall GPA. For example, Maram said that the class group presentation, which had 40 per cent mark allocation, was the main reason for her lower grade.

\section{Discussion of the findings and conclusion}

The findings revealed the range of the complex literacy and numeracy practices undertaken successfully by the students, including the integration of different semiotic systems. This indicates that they benefited from this task in different ways. The task developed students' understanding of marketing plans as part of business management. The students worked with and controlled the schematic structure of marketing plan reports, its professional language style, 
and general format guidelines. They also developed their analytical, critical, and interpersonal communication skills through interacting with peers and using quantitative data. However, the participants believed that they would have benefited more if they had practiced the task of writing a marketing plan in an authentic company rather than one that was based on hypothetical data through the SSM. Although the tutor provided them with feedback during class meetings, they thought they would have received more details if they practiced this task with employees in a company.

The results of the SF-MDA of the marketing texts (Section 3.2) showed that the students were apprenticed into the methods of writing marketing plan reports that included abstract complex technical lexis. This finding is in line with Alyousef's (2013) analysis of tertiary postgraduate finance texts. These complex literacy and numeracy practices are all salient and are likely to impact upon the students' work and life prospects. The results of the SF-MDA of the Transitivity system in the written elements revealed that material processes were the most frequently occurring process type, followed by relational processes (Table 1). The findings of the SF-MDA of the tables and figures revealed that the most frequent process type was implicit relational identifying processes that are factored into the financial tables, whereas material processes were the second most frequently occurring process type. The main function of the visual semiotics of the tables and graphs is to enable the organization of large amounts of raw data into a meaningful format. These visual semiotics employ structural condensation to encode meanings in the most economical manner. This provides an integrated way to understand the content, spot trends, and provide interpretive analytical analyses in the accompanying written text. All of these contribute to the process of drawing appropriate conclusions. This finding is in line with O'Halloran's (2008) argument that meaning is created in visual semiotic resources not only intrasemiotically but also intersemiotically through the interaction of visual semiotic resources with the accompanying written text. It also agrees with Alyousef's (2016) study of the textual relations in marketing plan texts where he suggested that new information can be inferred from the graphs within these texts. The written content accompanying the figures augments (or complements) the information presented in the figures. The figure-text relationship is one of 'enhancement', as the figure prompted the insights (or experiential meanings) presented in the written elements surrounding the figures. Zhao (2010: 209) used the term "ideational inflation" or intersemiotic coupling patterns to refer to the "shared ideational space" between two semiotic modes of meaning, namely written language, and graphs and tables. Zhao (2010: 209) used the term inflation 
The Representation of Experience in Undergraduate Business Students' Texts: A Functional Analysis of Multimodal Meaning Making Resources in Marketing Texts

"to encapsulate the complementary and synergetic nature of various modalities in meaning making".

The overall findings of the Transitivity system in the multisemiotic texts (both the written elements and the tables and figures) indicated that marketing plan texts almost equally intertwine relational identifying and material processes. This finding contrasts with a number of studies (Alyousef 2013, Alyousef \& Alsharif 2017, Alyousef \& Mickan 2016) that investigated the Transitivity system in tertiary finance, accounting, and management accounting texts, respectively. The findings in all these three studies revealed the extensive use of implicit relational identifying processes that are factored into the financial tables.

\section{Implications}

The multimodal exploration of the students' experiential meanings in the Integrated Marketing Topics course presents pedagogical implications for educators. Students' learning and understanding of the implicit meaning making resources in marketing can be developed when the writing processes are made explicit, that is, being "visible" and "comprehensible" (Alyousef \& Mickan 2016). Business students can be introduced into the ways of utilizing the meaning-making potential by providing them with the understanding of the relationships between the different modes of meaning available to them. These include not only the intrasemiotic shifts (or resemiotisation processes) between each numerical value and its corresponding period in a graph or table, but also the intersemiotic shifts from a diagrammatic and tabular form to written textual form. The text accompanying the tables and graphs needs to complement and be consistent with the visual semiotics. If the relationships between these different modes of meaning are made explicit, then students' learning experiences and understanding of the potential of the integration of the meaning making resources may be greatly enhanced.

Since this study was limited to an analysis of three students' texts and a tutor's two texts, there is no possibility to generalize the findings across the discipline from such a small data set. However, the study presents some implications in that it draws attention to the prevalence of multimodality as a given feature of the great majority of business marketing plans. The study has attempted to understand the relationship between the different modes used, and how these modes may complement each other in the quest to produce meaningful marketing plans. In general, the potential for further study in this area of semiotic complementarity in the field of business education is obvious. The use of several modes of meaning in texts in this field is commonplace. Analysis and interpretation of how these modes work separately and together will be useful to both teachers and students. 
Further studies can compare students' experiences of working with the SSM with those gained from working with employees in authentic workplace situations.

\section{Acknowledgement}

The author expresses his appreciation to the Deanship of Scientific Research at King Saud University and the Research Centre at the Faculty of Arts for funding the current article.

\section{References}

Alyousef, H. S. (2013) 'An investigation of postgraduate Business students' multimodal literacy and numeracy practices in Finance: A multidimensional exploration.' Social Semiotics 23(1), 18-46.

Alyousef, H. S. (2016) 'A multimodal discourse analysis of the textual and logical relations in marketing texts written by international undergraduate students.' Functional Linguistics (A Springer Open Journal) 3(3), 1-29.

Alyousef, H. S. (2017) 'A multimodal discourse analysis of textual cohesion in tertiary marketing texts written by international undergraduate students.' In: Pelkey J. (ed.) Semiotics 2016: Archaeology of Concepts (Yearbook of the Semiotic Society of America). Charlottesville, VA: U.S.: Philosophy Documentation Center. 99-122.

Alyousef, H. S. and Alsharif A. A. (2017) 'The experiential meaning in Saudi postgraduate Business students' multimodal accounting texts: A multidimensional exploration.' Australian Journal of Linguistics (AJL) 37(2), 219-251.

Alyousef, H. S. and Mickan, P. (2016) 'Literacy and numeracy practices in postgraduate management accounting.' In: Fidalgo, R., Olive, T., Archer, A. and Breuer, E. O. (eds) Studies in Writing: Vol. 33, Multimodality in Higher Education. Leiden and Boston: Brill Publishing. 216-240.

Baker, D., Street, B. and Tomlin, A. (2003) 'Mathematics as social: Understanding relationships between home and school numeracy practices.' For the Learning of Mathematics 23(3), 11-15.

Chandrasoma, R. (2007) Coping with Interdisciplinarity: Postgraduate Student Writing in Business Studies. Sydney: Faculty of Education, University of Technology.

Halliday, M. A. K. (1967) 'Notes on transitivity and theme in English: Part 2.' Journal of Linguistics 3(2), 199-244.

Halliday, M. A. K. (2014) Introduction to Functional Grammar. Revised by Christian M. I. M. Matthiessen. London and New York: Taylor \& Francis.

Jones, J. F. (1999) 'From silence to talk: Cross-cultural ideas on students' participation in academic group discussion.' English for Specific Purposes 18(3), 243-259.

Kress, G. and Van Leeuwen, T. (2006) Reading Images: The Grammar of Visual Design. London: Routledge.

Martinec, R. and Salway, A. (2005) 'A system for image-text relations in new (and old) media.' Visual Communication 4(3), 337-371.

O'Halloran, K. (1998) 'Classroom discourse in mathematics: A multisemiotic analysis.' Linguistics and Education 10(3), 359-388.

O'Halloran, K. (1999) 'Towards a systemic functional analysis of multisemiotic mathematics texts.' Semiotica 124(1-2), 1-30. 
O'Halloran, K. (2005) Mathematical Discourse: Language, Symbolism and Visual Images. London: Continuum.

O'Halloran, K. (2008) 'Mathematical and scientific forms of knowledge: A systemic functional multimodal grammatical approach.' In: Christie, F. and Martin, J. R. (eds) Language, Knowledge and Pedagogy: Functional Linguistic and Sociological Perspectives. London: Continuum. 205-236.

Pulendran, S., Speed R. and Widing, R. (2003) 'Marketing planning, market orientation and business performance.' European Journal of Marketing 37(3-4), 476-497.

Royce, T. (2002) 'Multimodality in the TESOL classroom: Exploring visual-verbal synergy.' TESOL Quarterly 36(2), 191-205.

Wood, B. M. (2013) Essential Guide to Marketing Planning. Sydney: Pearson Prentice Hall.

Zhao, S. (2010) 'Intersemiotic relations as logogenetic patterns: Towards the restoration of the time dimension in hypertext description.' In: Bednarek, M. and Martin, J. R. (eds) New Discourse on Language: Functional Perspectives on Multimodality, Identity, and Affiliation. London and New York: Continuum Int. Publishing Group. 195-218.

Hesham Suleiman Alyousef is an Assistant Professor at the Department of English and Literature at King Saud University in Riyadh, Saudi Arabia. Currently, he teaches and supervises a number of postgraduate students. He received his $\mathrm{PhD}$ in 2014 from the University of Adelaide, Australia. Dr. Alyousef has published three book chapters and a number of papers in refereed journals and journals listed in ISI. His research interests include systemic functional linguistics, multimodal discourse analysis, academic literacies, metadiscourse, assessment and evaluation tools for ESL/EFL students, and the use of Web 2.0 technology in higher education. He has over 30 years of experience in teaching $\mathrm{ESL} / \mathrm{EFL}$.

Address: Department of English Language and Literature, Faculty of Arts, King Saud University, Riyadh, Saudi Arabia. [e-mail: hesham@ksu.edu.sa] 